\title{
Article
}

\section{Observations by incoherent scatter radar of related D- and F-region structuring at very high latitude}

Hargreaves, J.K. and Birch, Martin John

Available at http://clok.uclan.ac.uk/37950/

Hargreaves, J.K. and Birch, Martin John (2018) Observations by incoherent scatter radar of related $D$ - and F-region structuring at very high latitude. Journal of Atmospheric and Solar-Terrestrial Physics, 174 . pp. 5-16. ISSN $1364-6826$

It is advisable to refer to the publisher's version if you intend to cite from the work. http://dx.doi.org/10.1016/j.jastp.2018.01.032

For more information about UCLan's research in this area go to http://www.uclan.ac.uk/researchgroups/ and search for < name of research Group>.

For information about Research generally at UCLan please go to http://www.uclan.ac.uk/research/

All outputs in CLoK are protected by Intellectual Property Rights law, including Copyright law. Copyright, IPR and Moral Rights for the works on this site are retained by the individual authors and/or other copyright owners. Terms and conditions for use of this material are defined in the policies page.

\section{CLoK}

Central Lancashire online Knowledge www.clok.uclan.ac.uk

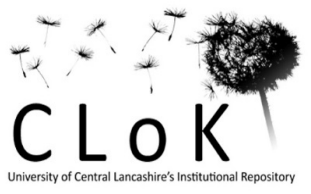




\section{Accepted Manuscript}

Observations by incoherent scatter radar of related D- and F-region structuring at very high latitude

J.K. Hargreavesa, M.J. Birch

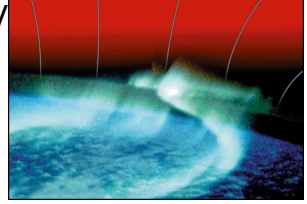

PII:

S1364-6826(17)30181-5

DOI:

10.1016/j.jastp.2018.01.032

Reference: $\quad$ ATP 4811

To appear in: Journal of Atmospheric and Solar-Terrestrial Physics

Received Date: 27 March 2017

Revised Date: 23 August 2017

Accepted Date: 1 January 2018

Please cite this article as: Hargreavesa, J.K., Birch, M.J., Observations by incoherent scatter radar of related D- and F-region structuring at very high latitude, Journal of Atmospheric and Solar-Terrestrial Physics (2018), doi: 10.1016/j.jastp.2018.01.032.

This is a PDF file of an unedited manuscript that has been accepted for publication. As a service to our customers we are providing this early version of the manuscript. The manuscript will undergo copyediting, typesetting, and review of the resulting proof before it is published in its final form. Please note that during the production process errors may be discovered which could affect the content, and all legal disclaimers that apply to the journal pertain. 
March 24, 2018

\title{
Observations by incoherent scatter radar of related D- and F-region structuring at very high latitude.
}

\author{
J.K. Hargreaves ${ }^{1,2}$
}

M. J. Birch ${ }^{1}$

(1) Jeremiah Horrocks Institute for Mathematics, Physics and Astronomy, University of Central Lancashire, Preston, UK.

(2) Department of Physics, Lancaster University, UK.

\begin{abstract}
Properties and associations of F- and D-region ionospheric structures during weak electron precipitation at very high latitude are investigated using the Longyearbyen incoherent scatter radar. The radio absorption deduced from the electron density observations revealed evidence of a persistent low-altitude absorption layer peaking at $80-85 \mathrm{~km}$. Inversion of the electron density profile to give an estimate of the incoming energetic electron spectrum suggests that its source may be the solar wind. Strong similarities are seen between variations in the $\mathrm{F}$ and $\mathrm{D}$ regions which suggest that the electron flux reaching the D-region is being modulated in energy by the variations of electron density in the F-region.
\end{abstract}




\section{Introduction}

Observations over the years have established the principal properties and behaviour of auroral radio absorption. The main technique of observation has been the riometer, single or multiple beam, which measures the absorption of cosmic radio noise in the ionosphere (Little and Leinbach, 1959; Detrick and Rosenberg, 1990). Using riometers it has been possible to study the statistical occurrences of auroral absorption with regard to magnetic latitude and local time, the variations typical of several types of event, and relations to geomagnetic activity and the interplanetary magnetic field (Hargreaves, 1966; Hargreaves and Cowley, 1967). Through comparisons with satellite measurements of energetic particle flux, and the direct measurement of electron densities in the lower ionosphere by incoherent scatter radar (Devlin et al., 1986), it has been shown that, in general, auroral absorption is a consequence of energetic electrons (in the tens of keV range) precipitating from the magnetosphere, and that, in general, these originate in the magnetotail region. This present investigation extends the above studies using observations by incoherent scatter radar at latitudes considerable higher than the maximum of auroral absorption occurrence.

\section{Observations}

In late February and early March of 2015, four runs were made with the 42m EISCAT Svalbard radar $(\mathrm{ESR})$ at Longyearbyen $\left(78.153^{\circ} \mathrm{N}, 16.029^{\circ} \mathrm{E}, \mathrm{L}\right.$-value 15.8$)$. The runs were from 17:00 to 23:00 UT on February 27 and 28, and from 05:00 to 11:00 UT on March 1 and 2, each covering 6 hours up to approximately midnight or noon in local magnetic time at the observing site. The ESR observations of electron density covered heights from about 30 to $504 \mathrm{~km}$ at 1 minute time resolution. The antenna was aligned along the geomagnetic field, at $8.4^{\circ}$ from the vertical 
with a half-power beamwidth of $\pm 0.3^{\circ}$. Figure 1 gives an overview of the ESR observations over heights between 78 and $466 \mathrm{~km}$, the range within which the observations were found to be valid.

The $38.2 \mathrm{MHz}$ imaging riometer at an adjacent site $\left(78.200^{\circ} \mathrm{N}, 15.820^{\circ} \mathrm{E}\right.$, which is only $5.22 \mathrm{~km} \mathrm{~N}$, and $4.83 \mathrm{~km} \mathrm{~W}$ of the radar) was operating during the ESR observations, as was the imaging riometer at Kilpisjärvi $\left(69.05^{\circ} \mathrm{N}, 20.79^{\circ} \mathrm{E}\right.$, L-value 5.9$)$, which is about $9.1^{\circ}$ of latitude $(1010 \mathrm{~km})$ to the south of the ESR.

\section{General conditions}

The observations were planned to coincide with the arrival of a fast solar wind stream at the magnetopause. In fact, the solar wind speed was typical of quiet conditions (300 to 400 $\mathrm{km} / \mathrm{s}$ ) during February 27. During the next three days the solar wind gradually assumed the characteristics of a high speed stream: the velocity increasing to a maximum of about $700 \mathrm{~km} / \mathrm{s}$, the number density usually $>10 / \mathrm{cm}^{3}$, and the interplanetary magnetic field fluctuating within about $10 \mathrm{nT}$. There were no proton events during the four days of observations, the $>10 \mathrm{MeV}$ proton flux being quiescent throughout the period.

As an indication of the general level of activity, Table 1 gives the ranges of the $\mathrm{K}_{p}$ index and of the radio absorption at Kilpisjärvi during the four observation periods. The geomagnetic activity increased from "quiet" on February 27, through "active" on February 28, to "minor storm" on March 1 and 2. The absorption observed at Kilpisjärvi is typical of the geomagnetic activity as indicated by $\mathrm{K}_{p}$ (Hargreaves, 1966).

According to the imaging riometer at Longyearbyen (magnetic latitude $75.5^{\circ}$ ), the absorption activity there was considerably weaker than at Kilpisjärvi (magnetic latitude $65.7^{\circ}$ ), being no greater than $0.2 \mathrm{~dB}$ and generally less than $0.1 \mathrm{~dB}$. Based on previous statistics (Hargreaves and Cowley, 1967), the absorption ratio between Longyearbyen and Kilpisjärvi should be about 
0.16 on average. The low level of activity at Longyearbyen was therefore consistent with what would be expected from previous results.

\section{D-region results from incoherent scatter radar - overview.}

The electron density observations of the D-region for heights from 78 to $100 \mathrm{~km}$ for the four 6-hour observation periods are shown in Figure 2. The temporal resolution is 1-minute, and the height resolution is between 2.4 and $3.6 \mathrm{~km}$, with an average of $3.1 \mathrm{~km}$. On February 27 there was some activity centred at $94 \mathrm{~km}$ after about 19:00 UT, but little obvious enhancement before then. February 28 was relatively quiet. On March 1 and 2 a stronger region of precipitation can be seen after 07:00 UT, starting at $100 \mathrm{~km}$ and spreading down to about $85 \mathrm{~km}$ by about 08:30 UT, then continuing until the end of the observing period. These times correspond approximately with the onset of solar illumination of the D-region during morning twilight at Longyearbyen. (Ground sunrise was at about 08:20 UT on March 1 and 2, and ground sunset was at about 15:35 UT on February 27 and 28.)

Figure 3 shows estimates of the $38.2 \mathrm{MHz}$ absorption distribution (in $\mathrm{dB} / \mathrm{km}$ ) over the same height range as Figure 2 (78 to $100 \mathrm{~km}$ ), derived by multiplying the electron density by the specific absorption coefficient (Table 2), and Figure 4 shows the total absorption over the same height range. The periods of stronger activity in Figure 3 show as enhancements in this total absorption, and at these low levels of absorption this is probably a more accurate determination than that by riometer. On February 27 there appears to be a variable absorption layer between about 81 and $88 \mathrm{~km}$ throughout the observation period. A similar though somewhat weaker layer is present on February 28, and also on March 1 and 2 until about 07:30 UT. In fact, this layer is seen throughout all four observation periods when it is not obscured by the higher layer. This study investigates two aspects of the lower layer: its general magnitude, and its variability. 


\section{Average profiles of the absorption layer, and a possible source}

Initial analysis of the absorption layer identified above has been restricted to periods when it is most clearly defined: February 27 (17:00-19:18 UT); February 28 (17:00-19:48 UT); and March 1 and 2 (05:00-07:30 UT). Figure 5(a) gives the average electron density profiles for each of these periods, and also the average over all four periods, for the height range $79-100 \mathrm{~km}$. The individual profiles differ by no more than a factor of 1.8 , and there is no evidence for any systematic time-of-day variation.

Figure 5(b) shows the corresponding height distributions of $38.2 \mathrm{MHz}$ radio absorption deduced from the electron density profiles. In total these amount to only 0.02 to $0.08 \mathrm{~dB}$, which would generally be undetectable by a riometer. In each case the peak of the absorption layer is between 80 and $85 \mathrm{~km}$. Most auroral absorption events peak around $90 \mathrm{~km}$ (Hargreaves et al., 2007), so it is significant that the layer in question is at a relatively low altitude. This means that the incoming particles producing this layer may be low in flux but must be relatively high in energy.

An inversion procedure (e.g. Devlin et al., 1986) has been applied to the average of the four electron density profiles to estimate the incoming spectrum of energetic electrons that could produce the observed layer. Figure 6 compares this spectrum with previous determinations based on a sample of typical auroral absorption events (Devlin et al., 1986), the electron densities in those events having been measured by the incoherent scatter radar at Tromsö. Describing the spectra in terms of a characteristic energy $\left(E_{0}\right)$, which assumes an exponential form, the fluxes at $40 \mathrm{keV}$ and $130 \mathrm{keV}$ give the values in Table 3 . The hardness value derived from the Longyearbyen low-altitude layer is clearly well above those for normal auroral absorption features.

The origin of the electron flux producing this low-altitude absorption layer is not obvious at 
first sight, but the solar wind may be a possible source. Measurements at the Wind spacecraft, about 230 Earth radii sunward of the magnetopause and near the L1 Lagrangian point, showed energetic electrons with an $\mathrm{E}_{0}$ value of $32.7 \mathrm{keV}$ (Table 3). This spectrum is included in Figure 6, and there is a clear similarity to that deduced for the low-altitude layer. There is, however, some difference between the intensities, the deduced fluxes at 40 and $130 \mathrm{keV}$ in this study being, on average, greater than those at Wind by about a factor of 3 . The similarity between the derived spectrum and that at Wind is nevertheless quite remarkable, considering the separation of the two locations. This appears to suggest that the source of the electron flux was not the magnetotail (by way of the substorm mechanism), but that the solar wind flux had more direct access to the magnetosphere at the latitude of Longyearbyen.

\section{Temporal fine structure}

\subsection{The lower D-region layer}

Figure 3 suggests that the lower layer has variations in electron density throughout the observation periods, and this structure appears to be quasi-periodic. Figure 7(1) gives the total absorption estimated for the height range 80.40 to $86.25 \mathrm{~km}$. To reduce the noise component, and to remove long-term trends, a smoothing procedure was used in which the 1-minute data were averaged over 6 minutes and this value was then divided by the average over 30 minutes (Figure $7(2)$ ). The intervals between successive peaks are summarised in Figure 8; only fluctuations where the peak-to-dip variation was at least $30 \%$ have been included, giving a total of 41 samples. The median inter-peak period for the low-altitude layer over all four days is 23 minutes, with quartiles at 17 and 33 minutes. 


\subsection{F-region behaviour}

The F-region is also subject to quasi-periodic variations, and between about 250 and $450 \mathrm{~km}$ the variability in electron density is remarkably similar at all heights. Taking the observations of February 27 as an example (Figure 9), the correlation coefficient between adjacent pairs of heights about $20 \mathrm{~km}$ apart is only once less than 0.9 , and for a separation of $154 \mathrm{~km}$ (heights 282 and $436 \mathrm{~km}$ ) it is still 0.86. (In Figure 9 the traces have been offset for clarity. The vertical bar indicates a factor of 10 in electron density, the same relative scale applying to each trace.)

To quantify the variations overall, the smoothing procedure of Section 6.1 was applied, and Figure 10 shows the variations for all four days in terms of the electron content ratio over the height range 237.50 to $354.85 \mathrm{~km}$ (the range within which the structures in Figure 9 are most similar). The intervals between successive peaks are summarised in Figure 11. The median inter-peak interval over the whole set of 53 samples is 22 minutes, which is very close to the value of 23 minutes for the low-altitude layer, and the quartiles are in fact the same.

Figure 12(a) gives the height profiles for a selected F-region peak and for the nearest dip on February 28, illustrating that in this case the F-region structure has a lower height limit and there is no direct connection down to the $\mathrm{E}$ and $\mathrm{D}$ regions. Repeating the comparison for 17 peak-dip pairs confirms that in all cases the vertical structuring ends above the E-region (Figure 12(b)), the median of these lower heights being at about $200 \mathrm{~km}$.

\subsection{Comparison of the timing of $\mathrm{F}$ and $\mathrm{D}$ region structures.}

For a detailed comparison, taking February 27 and March 1 as examples, and using the same smoothing procedure, Figure 13 shows the F-region structures as both electron density contours (a) and electron content (b), while (c) shows the variations in the absorption in the low-altitude layer. In both examples the periodicity in the F-region is similar to that in the lower layer. Not 
only are the periodicities statistically similar, but there are also instances when features such as peaks and dips occur almost simultaneously in electron content and absorption..

The median periodicities quoted above (23 minutes for the D-region, and 22 for the F-region) were based on the whole of the four 6-hour periods of observation. However, the structures wax and wane to some extent, and therefore, for a more rigorous comparison of detail, intervals were selected when the structures were most prevalent in both regions (Table 4). The time intervals and the 29 peaks selected for detailed comparison are marked on Figures 7(2) and 10. The 21 inter-peak periods (t) thereby selected for the D and F regions are compared in Figure 14. There is obviously a tendency to co-variation, and the correlation coefficient is 0.85 , though without the most remote point it falls to 0.64 . However, both these values are very significant statistically, the probability of them having occurred by chance being less than $1 \%$ (according to Fisher's z-test). The central line of the distribution is given by

$$
t_{D}=1.02 t_{F}-0.23
$$

This comparison, using selected inter-peak periods, supports the possibility of a causal connection between the structures in the $\mathrm{F}$ and $\mathrm{D}$ regions.

The delays between the $\mathrm{F}$ and $\mathrm{D}$ regions are now quantified for the same set of 29 selected peaks. For example, on February 27, a peak occurs in the F-region at 17:46 UT and the closest peak in the D-region occurs at 17:49, giving a delay of 3 minutes between the $\mathrm{F}$ and $\mathrm{D}$ peaks. The delays are summarised in Figure 15. A positive value means that the F peak precedes the D peak. The median is at about +3 minutes, and about half the values are within 2 minutes of that.

The D-region variations are presumably caused by variations in the incident electron flux. For a model we assume a D-region production rate given by $q_{0}+q_{1} \sin (w t)$. If the electron 
density is $\mathrm{N}$, the loss rate is $\alpha \mathrm{N}^{2}$ ( $\alpha$ being the recombination coefficient). Then

$$
\frac{d N}{d t}=q_{0}+q_{1} \sin (w t)-\alpha N^{2}
$$

In the absence of the varying component, $\mathrm{dN} / \mathrm{dt}=0$ and $\mathrm{q}_{0}=\alpha \mathrm{N}^{2}$. The average value of $\mathrm{N}$ for heights $80-85 \mathrm{~km}$ is about $1500 \mathrm{~cm}^{-3}$ (Figure 2), so, assuming $\alpha=1.6 \times 10^{-6} \mathrm{~cm}^{-3} \mathrm{~s}^{-1}$, the production rate $\mathrm{q}_{0}=3.15 \mathrm{~cm}^{-3} \mathrm{~s}^{-1}$. For a periodicity of 20 minutes, $w=5.24$ rad.s ${ }^{-1}$.

The solution to equation (2) is plotted in Figure 16, in which the amplitude of the electron density variation is $0.16 \mathrm{~N}_{0}$, resulting from an assumed $\mathrm{q}_{1}=0.50 \mathrm{q}_{0}$. The time delay between the maxima of production rate and electron density is 3.0 minutes, which agrees well with the median observed value. The same delay applies to the minima.

\subsection{A comparison of magnitudes}

The above analysis has concentrated on the timing of the peaks in the $\mathrm{F}$ and $\mathrm{D}$ regions. Figure 17 compares the magnitudes, using the relative values (the "ratios" (r), i.e. mean over 6 mins / mean over 30 minutes) as defined in Section 6.1. The derived regression equations for all 1-minute values (the black points only) from the selected periods (Table 4), 705 values in all, are

$\mathrm{r}_{D}$ on $\mathrm{r}_{F}$ :

$$
r_{D}=0.37 r_{F}+0.63
$$

$\mathrm{r}_{F}$ on $\mathrm{r}_{D}$ :

$$
r_{F}=0.22 r_{D}+0.78
$$

central line:

$$
r_{D}=1.30 r_{F}-0.29 .
$$


With this number of values, the correlation coefficient of 0.29 is significant, the probability of it having arisen by chance being less than $1 \%$.

The black points in Figure 17 are simultaneous $\mathrm{F}$ and $\mathrm{D}$ values at 1-minute intervals. However, we have seen that there is usually a small time difference between similar features (i.e. a peak or a dip). To take account of this, the regression analysis was repeated using just the readings for related peaks or dips (the red and green points in Figure 17). In that analysis the regression equations are -

$\mathrm{r}_{D}$ on $\mathrm{r}_{F}$ :

$$
r_{D}=1.13 r_{F}-0.10
$$

$\mathrm{r}_{F}$ on $\mathrm{r}_{D}$ :

$$
r_{F}=0.59 r_{D}+0.40
$$

central line:

$$
r_{D}=1.41 r_{F}-0.38
$$

The central lines are similar, but in the case of the peaks and dips the correlation coefficient is 0.82. The conclusion is that the variations in the D-region tend to be larger than those in the F-region by 30 to $40 \%$. The spread of $\mathrm{r}_{D} / \mathrm{r}_{F}$ for the peaks and dips is shown in Figure 18, with median values 1.10 and 0.94 , respectively.

\subsection{The possible role of wave-particle interaction}

The quasi-periodic variation of the lower D-region is probably due to a modulation of the incoming electron flux by the varying electron density of the F-region and protonosphere, involving wave-particle interaction. According to the theory of Kennel and Petschek (1966), whistler noise interacts with electrons of energy greater than $\mathrm{B}^{2} / 8 \pi \mathrm{N}$, B being the magnetic field strength and 
$\mathrm{N}$ the electron density. Thus, an increase in $\mathrm{N}$ will decrease the lower bound for the interaction and so increase the total precipitating flux. There should therefore be a variation in the shape of the electron spectrum and not merely in the magnitude of the flux.

Figure 19 shows the average electron density distribution against height for the whole observation period on February 27 (1700 - 2300 UT, blue curve), and also for times when the estimated absorption was above average $(0.0105-0.0140 \mathrm{~dB}$, red curve) and below average (0.0060 - $0.0089 \mathrm{~dB}$, black curve). The red and black curves represent maxima and minima in the absorption variation. The penetration depths of electrons of stated energy are also marked in Figure 19. Thus, the D-region variations of interest are due to electrons of at least $30 \mathrm{keV}$.

Figure 20 shows the electron spectra deduced from the electron density profiles. Whereas the flux falls steadily with increasing energy for the "low absorption" selection, the "high absorption" selection shows a dip at $60 \mathrm{keV}$ and a peak at $80-100 \mathrm{keV}$. It appears that this may be due to energisation of the incident electron flux in this range. In fact, a simple summation of the fluxes over the range 45-115 keV (Table 5) shows that the total electron flux in the range 50$110 \mathrm{keV}$ is virtually the same for each selection. Some of the $50-70 \mathrm{keV}$ population in the low absorption range is shifted to $80-100 \mathrm{keV}$ in the high absorption range. The spectrum deduced from the mean of all values gives a spectrum between those for the upper and lower ranges, and the constancy of total flux applies also to the derived spectrum (to within about $5 \%$.) It is suggested that the quasi-periodic structuring of the lower D-region is due to modulation of the electron spectrum by the energisation of electrons of $50-70 \mathrm{keV}$ up to $80-100 \mathrm{keV}$.

\section{Summary}

Observations of the electron density on February 27-28 and March 1-2 2015 with the EISCAT Svalbard radar revealed evidence of a low-altitude absorption layer peaking at $80-85 \mathrm{~km}$. The 
estimated absorption was only about $0.01 \mathrm{~dB}$ (at $38.2 \mathrm{MHz}$ ). However, most auroral absorption events peak around $90 \mathrm{~km}$, so, despite its low intensity, the low altitude of the layer suggests that it is due to electrons of relatively high energy. The spectrum estimated to be causing it appears to be similar to that measured by the Wind spacecraft close to the L1 point, suggesting that the source is within the solar wind.

The deduced absorption exhibits a quasi-periodic variation with amplitude about $15 \%$ and period about 23 minutes, which is remarkably similar to electron density structures in the F-region having average period 22 minutes though with a slightly smaller amplitude. The Dregion structures lag those in the F-region by about 3 minutes on average. A model computation assuming a sinusoidally varying electron flux indicates the same delay, though the magnitude of the flux variations (with amplitude about $50 \%$ of the mean value) is considerably larger than that of the electron density variations in the D-region.

The modulation of the electron flux is probably due to wave-particle interaction in the Fregion and protonosphere, causing pitch-angle diffusion. According to the theory of Kennel and Petschek (1966), the interaction operates for particle energies greater than $B^{2} / 8 \pi N(B=$ magnetic field strength, $\mathrm{N}=$ electron density), so that an increase in $\mathrm{N}$ reduces the threshold and thus increases the total scattering into the loss cone. Enhancements of the electron density in the F-region would therefore be expected to increase precipitation into the D-region.

\section{Discussion}

Associations between VLF emissions and cosmic radio noise absorption have been well established and investigated in detail in several earlier studies. Ecklund et al. (1965) showed that the occurrence of VLF chorus tended to increase with the amount of auroral absorption, though the relationship differed between the activity in the morning and evening sectors. Hargreaves 
and Bullough (1972) confirmed the relationship using VLF emissions observed on a satellite and $30 \mathrm{MHz}$ radio absorption at an auroral zone ground station. Hargreaves and Lyon (1973) then reported an increase in F-region electron content at the same high-latitude station during auroral absorption events in winter, though not in summer. Small-scale irregularity of the electron content, as evidenced by scintillation, also increased with periodic precipitation. Short duration ionisation enhancements have previously been identified at Longyearbyen during geomagnetically quiet conditions by Turunen et al. (Kavanagh, private communication), who suggested that they may be caused by high-speed solar wind streams. No relation to F-region structure was suggested, however.

There is, however, a problem in identifying the physical mechanism involved in the phenomena reported here. Horne et al. (2005) showed that energy may be transferred from lower to higher energies through the mechanism of wave-particle interaction. But this mechanism requires that the field lines are closed between hemispheres, and the Horne et al. theory applied to a much lower magnetic latitude (L value about 4.5). Moreover, the similarity to the spectrum of electrons in the solar wind (Section 5) implies the presence of field lines which are connected directly to the solar wind rather than to the opposite hemisphere. This would be consistent with the analysis of Hubert et al. (2010) showing a transition from closed to open field at about $70^{\circ}$ to $74^{\circ}$ magnetic latitude $(\mathrm{L}=8.5$ to 13.2$)$. The magnetic latitude of Longyearbyen $(\mathrm{L}=15.8)$ is just outside this range. The details of the mechanism remain an open question, therefore.

Acknowledgements We thank members of the EISCAT team for their assistance with the observations and the reduction of the data. We also thank P. Stauning of the Danish Meteorological Institute for sight of the Longyearbyen riometer data, and the referees for helpful comments regarding mechanisms. 


\section{References}

Birch, M.J., Hargreaves, J.K., Bromage, B.J.I, 2013. Properties of auroral radio absorption patches observed in the morning sector using imaging riometer and incoherent-scatter radar. Journal of Atmospheric and Solar-Terrestrial Physics. 105-106, 262-272.

Detrick, D.L. and Rosenberg,T.J., 1990. A phased-array radiowave imager for studied of cosmic noise absorption, Radio Science, 25, 325.

Devlin, T., Hargreaves, J.K., Collis, P.N., 1986. EISCAT observations of the ionospheric Dregion during auroral radio absorption events, J. Atmos. Terr. Phys., 48, 795-805.

Ecklund, W.L., Hargreaves, J.K., Pope, J.H., 1965. On the relation between auroral radio absorption and very low frequency emissions. Jnl. Geophys. Res., 70, 17, 4285-4292.

Hargreaves, J.K., 1966. On the variation of auroral radio absorption with geomagnetic activity, Planet. Sp. Sci., 14, 991-1006.

Hargreaves, J.K. and Cowley, F.C., 1967. Studies of auroral radio absorption events at three magnetic latitudes, 1. Occurrence and statistical properties of the events. Planet. Sp. Sci., 15, $1571-1583$.

Hargreaves, J.K. and Bullough, K., 1972. Mid-latitude VLF emissions and the mechanism of dayside auroral particle precipitation. Planet. Sp. Sci., 20, 803-807.

Hargreaves, J.K. and Lyon, G.F., 1973. The electron content of the auroral ionosphere during radio absorption events. Radio Science, 8, 1111-1117.

Hargreaves, J. K., Birch, M. J. and Bromage, B. J. I., 2007. D- and E-region effects in the auroral zone during a moderately active 24-h period in July 2005. Ann. Geophys. 25, 1837-1849. 
Horne, R.B., Thorne, R.M., Glauert, S.A., Albert, J.M., Meredith, N.P., Anderson, R.R., 2005. Timescale for radiation belt electron acceleration by whistler mode chorus waves, Jnl. Geophys. Res., 110, A03225, doi:10.1029/2004JA010811.

Hubert, B., Aikio, A.T., Amm, O., Pitkanen, T., Kauristie, K., Milan, S. E., Cowley, S. W. H., and Gerard, J.C., 2010. Comparison of the open-closed field line boundary location inferred using IMAGE-FUV SI12 images and EISCAT radar observations, Ann. Geophys., 28, 883-892, doi.org/10.5194/angeo-28-883-2010.

Kennel, C.F. and Petschek, H.E., 1966. Limit on stably trapped particle fluxes. J. Geophys. Res., 71, 1-28.

Little, C.G. and Leinbach, H., 1959. The riometer - a device for the continuous measurement of ionospheric absorption, Proc. I.R.E., 47, 315-326, February.

Rees, M.H., 1963. Auroral ionization and excitation by incident energetic electrons. Planet. Sp. Sci., 11, 1209-1218. 


\begin{tabular}{|c|c|c|c|c|}
\hline \multirow{2}{*}{ Date } & \multicolumn{2}{|c|}{ Time } & \multirow{2}{*}{$\mathrm{K}_{p}$} & Absorption at Kilpisjärvi (dB) \\
\cline { 2 - 3 } & Universal & Local & & \\
\hline \hline 2015 Feb 27 & $17: 00-23: 00$ & $18: 04-24: 04$ & $0+$ to $1+$ & 0 to 0.4 \\
2015 Feb 28 & $17: 00-23: 00$ & $18: 04-24: 04$ & 3 to $4-$ & 0 to 0.2 \\
2015 Mar 01 & $05: 00-11: 00$ & $06: 04-12: 04$ & $4-$ to $5+$ & 0 to 1.4 \\
2015 Mar 02 & $05: 00-11: 00$ & $06: 04-12: 04$ & $4+$ to $5+$ & 0 to 1.4 \\
\hline
\end{tabular}

Table 1: General level of activity during the four observation periods, according to (i) the $\mathrm{K}_{p}$ index (from World Data Centre for Geomagnetism, Kyoto), and (ii) the absorption at Kilpisjärvi. 


\begin{tabular}{|c|c|}
\hline Height $(\mathrm{km})$ & Specific Absorption Coefficient \\
\hline \hline 100 & $9.40 \mathrm{e}-08$ \\
96 & $1.58 \mathrm{e}-07$ \\
92 & $2.77 \mathrm{e}-07$ \\
88 & $4.58 \mathrm{e}-07$ \\
84 & $7.28 \mathrm{e}-07$ \\
80 & $1.30 \mathrm{e}-06$ \\
76 & $2.40 \mathrm{e}-06$ \\
\hline
\end{tabular}

Table 2: Values of specific absorption coefficient $\left(\mathrm{dB} / \mathrm{km}\right.$ for 1 electron $\mathrm{cm}^{-3}$, at $\left.38.2 \mathrm{MHz}\right)$ in the Dand E-regions (from Birch et al., 2013). 


\begin{tabular}{|l|c|c|c|c|c|}
\hline Study & Date and time $(\mathrm{UT})$ & $\mathrm{f}_{40}$ & $\mathrm{f}_{130}$ & $\mathrm{E}_{0} \mathrm{keV}$ & Group average $\mathrm{E}_{0}$ \\
\hline \hline & 1984 Dec14 20:16 & $1.7 \times 10^{5}$ & $8.0 \times 10^{2}$ & 16.8 & \\
Devlin et al. (1986) & 1985 Mar23 03:10 & $7.6 \times 10^{5}$ & $2.0 \times 10^{3}$ & 15.2 & 14.2 \\
& 1985 Mar23 03:50 & $3.1 \times 10^{5}$ & $1.5 \times 10^{2}$ & 11.8 & \\
\hline This study & 1985 Mar23 04:30 & $1.0 \times 10^{4}$ & $1.0 \times 10^{1}$ & 13.0 & \\
\hline Solar wind at L1 & 2015 Feb27-Mar02 & $2.5 \times 10^{1}$ & $2.8 \times 10^{0}$ & & \\
\hline
\end{tabular}

Table 3: Comparison of characteristic energies from the Devlin et al (1986) study, selected periods in the present study, and the solar wind electron flux at L1 for the same periods. $\left(\mathrm{f}_{k e V}\right.$ are fluxes with units $/ \mathrm{cm}^{2}$. s.sr.keV.) 


\begin{tabular}{|c|c|c|c|c|}
\hline Date & UT interval & Duration of interval (hrs:mins) & Number of peaks & Number of inter-peak periods \\
\hline \hline Feb 27 & $17: 00-19: 30$ & $2: 30$ & 5 & 3 \\
& $21: 30-22: 30$ & $1: 00$ & 3 & 2 \\
\hline Feb 28 & $17: 00-18: 45$ & $1: 45$ & 5 & 4 \\
\hline Mar 01 & $05: 00-06: 20$ & $1: 20$ & 3 & 2 \\
\hline Mar 02 & $08: 10-11: 00$ & $2: 50$ & 7 & 2 \\
\hline Total & $09: 00-07: 00$ & $2: 00$ & 3 & 2 \\
\hline
\end{tabular}

Table 4: Periods selected for detailed comparison of F- and D-region fluctuations. 


\begin{tabular}{|c|c|c|c|c|c|}
\hline \multirow{2}{*}{ Energy } & \multicolumn{5}{|c|}{ Flux $\left(\mathrm{x} 10\right.$ to give $\left.\mathrm{cm}^{-2} \cdot \mathrm{s}^{-1} \cdot \mathrm{sr}^{-1}\right)$} \\
\cline { 2 - 6 } & Low. abs. range & High abs. range & Mean of all values & Difference (high - low) & Ratio (high/low) \\
\hline \hline 50 & 57 & 28 & 46 & -29 & 0.49 \\
60 & 37 & 13 & 26 & -24 & 0.35 \\
70 & 27 & 23 & 26 & -4 & 0.85 \\
80 & 19 & 36 & 24 & +17 & 1.9 \\
90 & 12 & 33 & 16 & +21 & 2.8 \\
100 & 7 & 20 & 10 & +13 & 2.9 \\
110 & 4 & 8 & 6 & +4 & 2.0 \\
\hline Totals & 163 & 161 & 154 & & \\
\hline
\end{tabular}

Table 5: Average flux versus energy for the lower and upper absorption selections, and for the mean of all values. The energies are for the middle of each $10 \mathrm{keV}$ band. 
Figure 1: ESR electron density during the observing periods on each of the four days, for the height range 78-466 km, at 1-min temporal resolution: (a) February 27; (b) February 28; (c) March 1; (d) March 2. (These are log plots, with the scale showing linear values $\left(x 10^{9} \mathrm{~m}^{-3}\right)$ for ease of interpretation. The "speckling" is from bad data, mainly between 100 and $200 \mathrm{~km}$.) 
Figure 2: Electron density from 78 to 100 km: (a) February 27; (b) February 28; (c) March 1; (d) March 2. (These are log plots, with the scales showing linear values $\left(\mathrm{x} 10^{9} \mathrm{~m}^{-3}\right)$.) 
Figure 3: Deduced absorption from 78 to 100 km: (a) February 27; (b) February 28; (c) March 1; (d) March 2. (These are log plots, with the scales showing linear values $\left(\mathrm{x} 10^{-5} \mathrm{~dB} / \mathrm{km}\right)$. The plots use somewhat different scales, each chosen to highlight the low altitude layer.) 
Figure 4: Deduced total absorption (dB) from 78 to 100 km: (a) February 27; (b) February 28; (c) March 1; (d) March 2 . 
Figure 5: (a) Mean electron density $\left(\mathrm{cm}^{-3}\right)$ from 79 to $100 \mathrm{~km}$, averaged over the selected UT periods. (b) Deduced absorption profiles $(\mathrm{dB} / \mathrm{km})$ deduced from the electron densities in (a). (The thick solid lines are the geometric means of the selected periods.) 
Figure 6: Spectra of energetic electron flux: (red) average spectrum of precipitating electrons during the selected UT periods; (green) average spectrum of solar wind electrons observed by the Wind spacecraft for the same UT periods; (black) examples from Devlin et al. (1986). 
Figure 7: Deduced absorption from 80.40 to 86.25 km: (a) February 27; (b) February 28; (c) March 1; (d) March 2. Panels (1): at 1-minute resolution. Panels (2): relative values determined by taking the ratio of 6 -min to 30-min smoothing, in order to remove short-term noise and longterm variations. The dashed lines and asterisks mark the time intervals and peaks selected in Section 6.3 and Table 4. 
Figure 8: Histograms of the inter-peak periods of smoothed absorption from Figure 7(2): (a)

February 27; (b) February 28; (c) March 1; (d) March 2; (e) Total. The medians are shown in (a) to (e), and the quartiles in (e). 
Figure 9: Electron density variations on a log scale (1-minute data) in the F-region on February 27 at the indicated heights. The vertical bar shows a factor of 10 variation in electron density. 
Figure 10: Relative electron content ratio over 237.5 to $354.85 \mathrm{~km}$ : (a) February 27; (b) February 28; (c) March 1; (d) March 2. (Determined by taking the ratio of 6-min to 30-min smoothing, to remove both short-term noise and long-term variations. The dashed lines and asterisks mark the time intervals and peaks selected in Section 6.3 and Table 4.) 
Figure 11: Histograms of the inter-peak periods of smoothed TEC from Figure 10: (a) February 27; (b) February 28; (c) March 1; (d) March 2; (e) Total. The medians are shown in (a) to (e), and the quartiles also in (e). 
Figure 12: (a) Electron density profile of a selected peak on February 28, and its adjacent dip.

(b) Statistics of the height below which the vertical structuring between the peak-dip pairs ceases, for 17 selected pairs. 
Figure 13: (a) Electron density contours in the F-region. (b) Electron content from 237.5 to $354.85 \mathrm{~km}$ (from Figure 10). (c) Deduced absorption from 80.40 to $86.25 \mathrm{~km}$ (from Figure 7). Panels (1): February 27. Panels (2): March 1. (All determined by taking the ratio of 6 -min to 30-min smoothing, to remove both short-term noise and long-term variations.) 
Figure 14: Comparison of the 21 inter-peak periods in the F and D regions for the selected UT intervals, showing histograms with medians (M), and regression lines with the common central point $(+)$. 
Figure 15: Histogram of delays between $\mathrm{F}$ and $\mathrm{D}$ region peaks. (A positive delay means that the F peak occurred before the $\mathrm{D}$ peak). 
Figure 16: The solution to equation (2), showing the electron density (N) due to a production rate (q). The dotted lines indicate the 3-minute delay between $\mathrm{q}$ and $\mathrm{N}$ at times of maxima and minima. 
Figure 17: Comparison of the magnitudes of the F- and D-region ratios, for all 705 1-minute values (black crosses) in the selected periods in Table 4 . The 29 selected peaks are shown in red, with the 20 associated dips (where applicable) in green. The medians (M) and the standard errors (blue bars on the axes) are also marked. 
Figure 18: (a) Histogram of (D peak magnitude)/(F peak magnitude). (b) Histogram of (D dip magnitude)/(F dip magnitude). $\mathrm{M}=$ median. 
Figure 19: Average electron density profiles for 17:00 - 23:00 UT on February 27. Red: upper absorption range. Black: lower absorption range. Blue: all values. The electron penetration depths for a range of energies are shown on the right (after Rees, 1963). 
Figure 20: Deduced electron spectra for the selections in Figure 19. The dashed line shows the range of energies used in Table 5. The spectrum measured at Wind for the same period of time is shown in green (allowing 1 hour delay). 